\title{
Annual Number of Citations in Scientific Publications
}

\author{
Yusuf Emrah Eyi ${ }^{1}$, Ümit Kaldırım²
}

\author{
${ }^{1}$ Emergency Service, President Guard Regimen, Ankara, Turkey \\ ${ }^{2}$ Emergency Service, Siirt Military Hospital, Siirt, Turkey
}

\section{Dear Editor,}

We have read the article titled "The Place of Turkey in the Science World (II) (2008-2012)," written by Köksoy et al. (1) and published in the 2nd issue of your journal in 2014, with great interest. We thank them for sharing their experience with us. However, we think that the authors made an error in the calculation of the number of citations while reporting the results of the study, and we want to highlight this point.

The authors evaluated the number of citations per year for the articles published worldwide after 2008, and consequently, they reported a decrease in the number of citations. According to the existing evaluation method, although the citations for the articles in 2008 are evaluated over a period of 6 years, two-year citations can be evaluated for the articles published in 2012. Thus, the number of citations for the studies published in recent years will be inevitably lower. We think that objective and accurate results can be obtained by evaluating the articles of each year after equal periods.

We congratulate Köksoy et al. (1) on their valuable study and present our best compliments.

\section{REFERENCES}

1. Köksoy FN, Gönüllü D, Gedik ML, Demiray O, Er M. The Place of Turkey in the Science World (II) (2008-2012). JAREM 2014; 2: 49-81. 